\title{
Dynamic Electropulsing Induced Phase Transformations in a Furnace Cooled Zn-Al Based Alloy (ZA22)
}

\author{
S. To ${ }^{1}$, Y. H. Zhu ${ }^{1, *}$, W. B. Lee ${ }^{1}$ and X. M. Liu ${ }^{2}$ \\ ${ }^{1}$ State Key Laboratory in Ultra-precision Machining Technology, Department of Industrial and Systems Engineering, \\ The Hong Kong Polytechnic University, P. R. China \\ ${ }^{2}$ Hefei National Laboratory for Physical Science at Microscales, University of Science and Technology of China, Hefei, P. R. China
}

Multi-phase identification and phase transformations in a dynamic electropulsing treated $\mathrm{Zn}$-Al based alloy (ZA22) were studied by using backscattered scanning electron microscopy (BSEM) and electron back-scattered diffraction techniques (EBSD). By using EBSD, two hcp phases $\eta^{\prime} \mathrm{s}$ and $\eta_{\mathrm{T}}^{\prime}$ with a small difference of about $1 \%$ in lattice parameters (c/a) were discriminated. Two stages of phase transformations: (a) $\eta_{\mathrm{S}}^{\prime} \rightarrow \eta^{\prime} \mathrm{T}+\varepsilon_{\mathrm{T}}^{\prime}+\alpha_{\mathrm{T}}^{\prime}$ and $\varepsilon+\alpha \rightarrow \mathrm{T}^{\prime}+\eta$ (in a way of quenching), and (b) $\mathrm{T}^{\prime}+\eta \rightarrow \varepsilon+\alpha$ and $\eta_{\mathrm{T}}^{\prime}+\varepsilon_{\mathrm{T}}^{\prime}+\alpha_{\mathrm{T}}^{\prime} \rightarrow \eta_{\mathrm{S}}^{\prime}$ (in a way of upquenching), were detected. It was found that dynamic electropulsing was less effective in accelerating phase transformations than static electropusling. The mechanism of dynamic electropulsing induced phase transformations is discussed from the point view of Gibbs free energy and electropulsing kinetics. [doi:10.2320/matertrans.M2010130]

(Received April 12, 2010; Accepted August 18, 2010; Published October 6, 2010)

Keywords: electropulsing, tensile deformation, electron back-scattered diffraction (EBSD), phase transformations, zinc-aluminum alloy

\section{Introduction}

Metallic alloys always suffer various external and internal stresses during manufacture and subsequently in service. The external and internal stresses accelerate microstructural change and phase transformation, and affect the properties of the alloy and the efficiency of the processes. It is important to reduce the residual stresses inside the alloys. The newly developed process, electropulsing treatment (EPT) was found to be able to reduce the residual external stresses in the alloys. ${ }^{1)}$ As an alternative to the traditional thermal and thermo-mechanical processes, EPT has attracted a great deal of attention. Extensive studies have been carried out in materials science and engineering, such as electroplastisity, ${ }^{1-6)}$ electromigration, ${ }^{7,8)}$ recrystallization, ${ }^{9-12)}$ amorphous nanocrystallization ${ }^{13,14)}$ and phase transformation. ${ }^{15-24)}$

As a new kind of driving force for phase transformations, electropulsing is more powerful and more effective than thermal and thermo-mechanical energies. Traditional thermodynamics are not sufficient to explain the elctropulsing behaviors. Fortunately, a new field of materials science and engineering named "electrodynamics" is emerging. Studies of the effect of electropulsing on phase transformation and properties of alloys, on the mechanism of electropulsing, such as on the interaction between electrons and atom lattices, movement and annihilation of dislocations, etc. are mainly dealt with in "Electrodynamics". This is of great theoretical significances and practical importance.

There are two practical types of applying electropulsing: static electropulsing and dynamic electropulsing. The former combines a thermal process and electropulsing. The latter is a complex thermal process, which combines simultaneously both electropulsing and tensile deformation.

The effects of the static electropulsing on both microstructure and plastic elongation of the alloy have been studied previously. ${ }^{6,21)}$ It was detected that a static electropulsing

*Corresponding author, E-mail: yaohuazhu@hotmail.com tremendously accelerated diffusional phase transformations by a factor of at least 6000 times, compared with that achieved in ageing processes. ${ }^{20)}$

As part of a systematic investigation into this newly developed process, the present paper deals with the effects of the dynamic electropulsing on phase transformations of a furnace cooled $\mathrm{Zn}$-Al based alloy (FC-ZA alloy) are studied.

\section{Experimental Procedures}

A cast ingot of $\mathrm{Zn}-\mathrm{Al}$ based alloy of eutectoid composition $\mathrm{Zn}-22.1 \% \mathrm{Al}-2.6 \mathrm{Cu}$ (in mass\%) was repeatedly extruded at $250^{\circ} \mathrm{C}$, to produce gross wire of $9.5 \mathrm{~mm}$ in diameter. The wire was then repeatedly cold-drawn. Before each cold drawing, the wire was tempered at $250^{\circ} \mathrm{C}$ for $20 \mathrm{~min}$. The as-received wire was reduced to $1.5 \mathrm{~mm}$ in diameter. Before EPT, the wire was solution treated at $350^{\circ} \mathrm{C}$ for four days, then naturally cooled inside the furnace, i.e. furnace cooled (FC) to the ambient temperature. The heat treated alloy wire was cut into pieces of $100 \mathrm{~mm}$ length. The dynamic EPT was performed on the wire specimens being tensile deformed. Multiple electropulses were applied on two electrical contacts with a distance of $80 \mathrm{~mm}$. A self-made electropulsing generator was applied to discharge positive direction multiple pulses with various current intensities, $5 \mathrm{~A}, 10 \mathrm{~A}$, $15 \mathrm{~A}, 20 \mathrm{~A}$ and $30 \mathrm{~A}$, through adjusting the controlling parameters. The frequency of the multiple electropulses was chosen as $100 \mathrm{~Hz}$, respectively. The pulse duration was kept to about $2300 \mu \mathrm{s}$. A jet oil cooling system was used to cool and protect the surface of the specimens. The surface temperature of the specimens was measured by a thermocouple for each test. Using an oscilloscope with a Hill effect component, various parameters of the electropulsing, such as the peak density of current, $j_{\mathrm{m}}$ and the mean-root-square of the current density, $j_{\mathrm{e}}$, were determined. The results are listed in Table 1.

The tensile tests were carried out at about ambient temperature $\left(28^{\circ} \mathrm{C}\right)$ with a crosshead speed, i.e. deformation 
Table 1 Operation parameters of the dynamic electropulsing of FC ZA22 alloy wires.

\begin{tabular}{cccccc}
\hline $\begin{array}{c}\text { Current } \\
\text { Intensity }\end{array}$ & $\begin{array}{c}\text { Frequency } \\
(f \mathrm{~Hz})\end{array}$ & $\begin{array}{c}\text { Peak current } \\
\text { density } \\
\left(J_{\mathrm{m}}, \mathrm{A} / \mathrm{mm}^{2}\right)\end{array}$ & $\begin{array}{c}\text { MRS } \\
\left(J_{\mathrm{e}}, \mathrm{A} / \mathrm{mm}^{2}\right)\end{array}$ & $\begin{array}{c}\text { Duration of } \\
\text { pulse }(\mu \mathrm{s})\end{array}$ & $\begin{array}{c}\text { Temp. } \\
\left({ }^{\circ} \mathrm{C}\right)\end{array}$ \\
\hline $30 \mathrm{~A}$ & 100 & 104.39 & 33.86 & 2300 & 50 \\
\hline $20 \mathrm{~A}$ & 100 & 80.23 & 25.02 & 2300 & 42 \\
\hline $15 \mathrm{~A}$ & 100 & 63.84 & 17.79 & 2300 & 30 \\
\hline $10 \mathrm{~A}$ & 100 & 56.08 & 15.10 & 2300 & 28 \\
\hline $5 \mathrm{~A}$ & 100 & 35.80 & 8.77 & 2300 & 27 \\
\hline
\end{tabular}

rate, of $2 \mathrm{~mm} / \mathrm{min}$ (4.7 time faster than normal deformation rate of $0.42 \mathrm{~mm} / \mathrm{min}$ for the $\mathrm{Zn}-\mathrm{Al}$ alloys).

The microstructural changes and phase transformations were examined using scanning electron microscopy in the back-scattered electron mode (BSEM) to obtain a medium resolution of atomic number contrast among the various phases involved. The BSEM based electron back-scattered diffraction technique (EBSD) is utilized to determine the local crystal structure and orientation of materials. The electron back-scattered Kikuchi diffraction patterns (EBKDP) are detected in SEM simply from bulk alloy specimens, instead of thin foil specimens using the transmission electron microscopy (TEM). The EBSD can also facilitate evidence of phase transformation by discriminating between phases having close or even identical crystal structures. ${ }^{25-28)}$ An EBSD examination was carried out on the Leo 1530 FESEM using a commercially available software from HKL Technology APS Ltd. (Oxford, UK). In performing EBSD, the specimens were tilted at 70 degrees. The electron microscope scanned in step sizes of $0.3 \mu \mathrm{m}$.

\section{Results}

The microstructure of the bulk part of the non dynamic EPT FC-ZA alloy specimens consisted of two lamellar structures (coarse and fine lamellae) with light imaged Znrich hexagonal close packed (hcp) phase particles: residual supersaturated $\eta_{\mathrm{S}}^{\prime}$ and $\varepsilon_{\mathrm{T}}^{\prime}\left(\mathrm{Zn}_{4} \mathrm{Cu}\right)$.

Part of the $\eta_{\mathrm{S}}^{\prime}$ had decomposed to metastable phases, $\eta_{\mathrm{T}}^{\prime}$, $\varepsilon^{\prime}{ }_{\mathrm{T}}$ and dark imaged $\alpha^{\prime}{ }_{\mathrm{T}}$ phase, as shown in Fig. 1(a1). The coarse lamellar was from the decomposition of a supersaturated Zn-rich $\beta_{\text {S }}^{\prime}$ of body center cubic (bcc) structure and the fine lamellar was from the decomposition of a supersaturated Al-rich $\alpha^{\prime}$ s phase.

In the bulk part of the dynamic EPT FC-ZA alloy specimen, the decomposition of the $\eta_{\mathrm{S}}^{\prime}$ phase, $\eta_{\mathrm{S}}^{\prime} \rightarrow \eta_{\mathrm{T}}^{\prime}+$ $\varepsilon_{\mathrm{T}}^{\prime}+\alpha_{\mathrm{T}}^{\prime}$ was developed when the current density of electropulsing increased. One of the characteristics of the transformation was that the amount of the $\alpha^{\prime}{ }_{\mathrm{T}}$ precipitates increased at grain boundaries of the light imaged particles of the $\mathrm{Zn}$-rich phases. When increasing current intensity up to $30 \mathrm{~A}$, the amount of the dark imaged $\alpha^{\prime} \mathrm{T}$ precipitates increased, as indicated by arrows in Fig. 1(a).

For a comparison, the FC-ZA based alloy specimens were statically electropulsing-treated under various current intensities, and the static EPT specimens were then tensile deformed at ambient temperature. BSEM images of the bulk parts of the tensile deformed non-EPT and static EPT FC-ZA alloy specimens are shown in Fig. 1(b). ${ }^{6}$

In addition of the induced phase transformation, $\eta_{\mathrm{S}}^{\prime} \rightarrow \eta_{\mathrm{T}}^{\prime}+\varepsilon_{\mathrm{T}}^{\prime}+\alpha_{\mathrm{T}}^{\prime}$, another four phase transformation, $\varepsilon+\alpha \rightarrow \mathrm{T}^{\prime}+\eta$ was detected in the bulk part of the static EPT FC-ZA alloy specimens. ${ }^{6)}$ As one of the products of the four phase transformation, the amount of the grey imaged $\mathrm{T}^{\prime}$ precipitates increased when the current density of the elctropulsing increased, as indicated by arrows in Fig. 1(b2)(b5). ${ }^{6}$ The $\mathrm{T}^{\prime}$ phase is of body center cubic (bcc) structure. It can be clearly seen that phase transformation rates were increased much more in the static EPT FC-ZA alloy specimens, than in the dynamic EPT FC-ZA alloy specimens.

In the neck zone of the specimen, with addition of tensile stress the phase transformations: $\eta_{\mathrm{S}}^{\prime} \rightarrow \eta_{\mathrm{T}}^{\prime}+\varepsilon_{\mathrm{T}}^{\prime}+\alpha_{\mathrm{T}}^{\prime}$ and $\varepsilon+\alpha \rightarrow \mathrm{T}^{\prime}+\eta$, were accelerated. Shown in Fig. 2(a) is BSEM images of the neck zone of the dynamic EPT alloy specimens. Accompanying the further development of the precipitation of the dark imaged $\alpha^{\prime}$ T phase, the grey imaged $\mathrm{T}^{\prime}$ phase precipitates appeared in the neck zone of the dynamic EPT FC-ZA alloy specimen, as indicated by arrows in Fig. 2(a). This means that the four phase transformation, $\varepsilon+\alpha \rightarrow \mathrm{T}^{\prime}+\eta$, occurred. With increasing tensile stress, the amount of the $\mathrm{T}^{\prime}$ precipitates increased to a maximum and the final stable state was reached in the neck zone near the rupture part of the specimen, as shown in Fig. 2(b).

In the rupture part of the dynamic 30A-EPT specimen, it was found that the amount of the $\mathrm{T}^{\prime}$ phase precipitate decreased, as shown in Fig. 2(c). This implies that a reverse phase transformation: $\mathrm{T}^{\prime}+\eta \rightarrow \varepsilon+\alpha$, occurred.

In order to confirm the above phase transformations, EBSD was carried out accordingly. In previous studies, the phase transformations: $\eta_{\mathrm{S}}^{\prime} \rightarrow \eta_{\mathrm{T}}^{\prime}+\varepsilon_{\mathrm{T}}^{\prime}+\alpha_{\mathrm{T}}^{\prime}$ and $\varepsilon+\alpha \rightarrow$ $\mathrm{T}^{\prime}+\eta$, were detected in the EPT ZA alloy (ZA22), the TEM bright field images of which are shown in Fig. 3(a) and (b), respectively. ${ }^{5,20)}$ Lattice parameters of the five phases involved in the above mentioned phase transformations: $\eta_{\mathrm{S}}^{\prime}, \eta_{\mathrm{T}}^{\prime}, \varepsilon_{\mathrm{T}}^{\prime}, \alpha_{\mathrm{T}}^{\prime}$ and $\mathrm{T}^{\prime}$, were determined using TEM examination $^{5,20)}$ and listed in Table 2 . It is noticed that the two phases: $\eta_{\mathrm{S}}^{\prime}$ and $\eta_{\mathrm{T}}^{\prime}$ are of the same hcp microstructure, the $c / a$ of which is 1.818 and 1.837 , respectively. The difference in lattice parameters $c / a$ is only about $1 \%$. By using those previously determined lattice parameters of the five phases, the EBSKDP were generated by scanning selected areas of $1.35 \times 10^{3}(\mu \mathrm{m})^{2}$ in the BSEM images. EBSD mapping of the phases was realized and indexed automatically after subtracting the background noise.

By using EBSD, two hep phases $\eta_{\mathrm{S}}^{\prime}$ and $\eta_{\mathrm{T}}^{\prime}$ with a small difference of about $1 \%$ in lattice parameters (c/a) were discriminated, as shown in Fig. 4(a1)-(a5). Shown in Fig. 4(a) are the EBSD mappings of the phases of $\eta_{\text {s }}^{\prime}$ (blue in color) and $\eta_{\mathrm{T}}^{\prime}$ (red in color) in the bulk parts of the nonEPT (1), 10A-EPT (2), and 30A-EPT FC-ZA alloy specimens, and in the neck zone (near the rupture part) (4) and the rupture part (5) of the 30A-EPT FC-ZA alloy specimens. Fractional EBSD intensities of the phases: $\eta_{\mathrm{S}}^{\prime}$ and $\eta_{\mathrm{T}}^{\prime}$, and their ratios $\left(\eta_{\mathrm{S}}^{\prime} / \eta_{\mathrm{T}}^{\prime}\right)$, are listed in Table 3 . The ratios $\left(\eta_{\mathrm{S}}^{\prime} / \eta_{\mathrm{T}}^{\prime}\right)$, represent the changes of relative amounts of the phases of $\eta_{\mathrm{S}}^{\prime}$ and $\eta_{\mathrm{T}}^{\prime}$ and direction of the decomposition of the phases of $\eta_{\mathrm{S}}^{\prime}$ and $\eta_{\mathrm{T}}^{\prime}$. In the bulk part of the dynamic 30A 

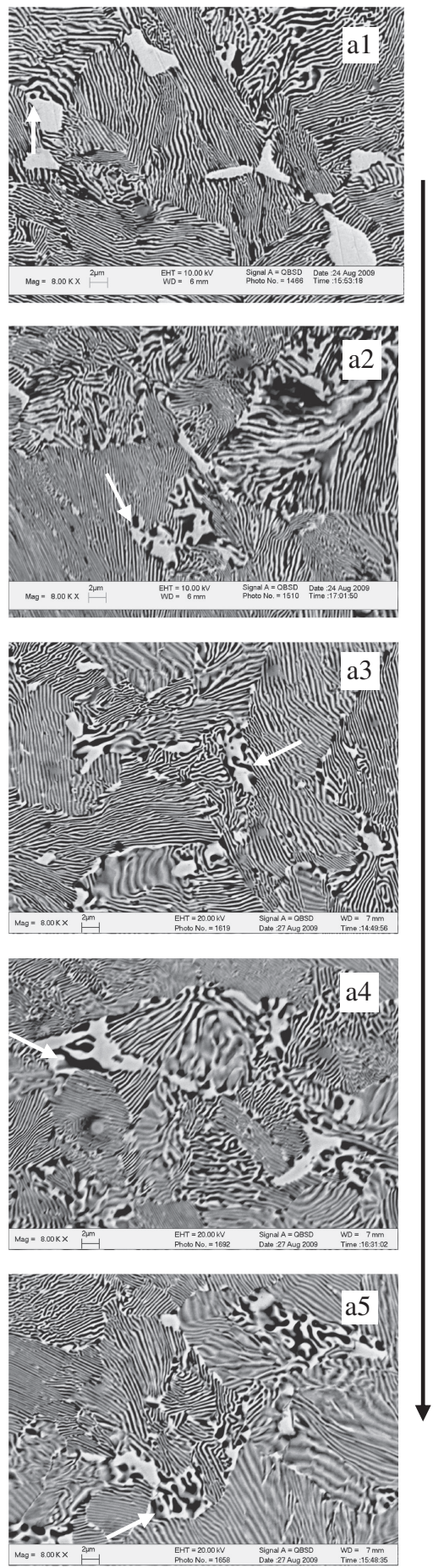
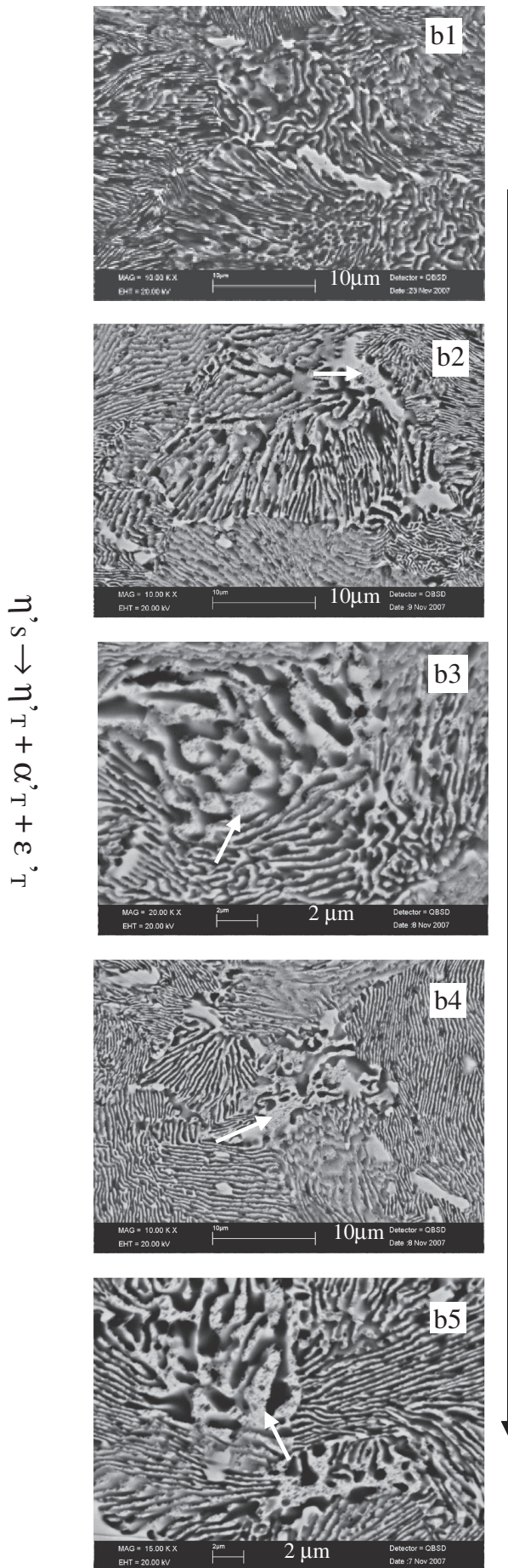

3
$\downarrow$
$\downarrow$
$\exists$
-1
+
8
-1
+
0
-1
0
0
8
+
0
$\downarrow$
-1
+
$\Xi$

Fig. 1 BSEM images of the bulk part of the tensile deformed non-EPT (a1), (b1) and dynamic EPT (a2)-(a5), and static EPT (b2)-(b5) FC ZA alloy specimens with various current intensities: (1) non-EPT, (2) 10A, (3) 15A, (4) 20A, (5) 30A.

EPT specimen, the ratio $\left(\eta_{\mathrm{S}}^{\prime} / \eta_{\mathrm{T}}^{\prime}\right)$ was 1.5 . After $30 \mathrm{~A}-\mathrm{EPT}$, the ratio $\left(\eta_{\mathrm{S}}^{\prime} / \eta_{\mathrm{T}}^{\prime}\right)$ was decreased to 1.2 . This means that when the current intensity increased, the decomposition of the $\eta_{\mathrm{S}}^{\prime}, \eta_{\mathrm{S}}^{\prime} \rightarrow \eta_{\mathrm{T}}^{\prime}+\varepsilon_{\mathrm{T}}^{\prime}+\alpha_{\mathrm{T}}^{\prime}$, developed in the bulk part of the dynamic EPT specimen. With addition of the tensile stress, the ratio $\left(\eta_{\mathrm{S}}^{\prime} / \eta_{\mathrm{T}}^{\prime}\right)$ further decreased to the minimum, 0.8 . This implies that $\eta_{\mathrm{S}}^{\prime} \rightarrow \eta_{\mathrm{T}}^{\prime}+\varepsilon_{\mathrm{T}}^{\prime}+\alpha_{\mathrm{T}}^{\prime}$ was completed in the neck zone of the dynamic EPT ZA alloy specimen.

In the rupture part of the specimen, the ratio $\left(\eta_{\mathrm{S}}^{\prime} / \eta^{\prime} \mathrm{T}\right)$ was slightly increased 0.9. This implies that a reverse phase transformation: $\eta_{\mathrm{T}}^{\prime}+\varepsilon^{\prime}{ }_{\mathrm{T}}+\alpha^{\prime}{ }_{\mathrm{T}} \rightarrow \eta_{\mathrm{S}}^{\prime}$ started to occur. Both
$\eta_{\mathrm{S}}^{\prime} \rightarrow \eta_{\mathrm{T}}^{\prime}+\varepsilon_{\mathrm{T}}^{\prime}+\alpha_{\mathrm{T}}^{\prime}$ and $\eta_{\mathrm{T}}^{\prime}+\varepsilon_{\mathrm{T}}^{\prime}+\alpha_{\mathrm{T}}^{\prime} \rightarrow \eta_{\mathrm{S}}^{\prime}$ are shown schematically in Table 3.

EBSD mapping of the $\mathrm{T}^{\prime}$ (yellow in color) and $\varepsilon^{\prime}{ }_{\mathrm{T}}$ (green in color) is shown in Fig. 4(b). The fractional EBSD intensities of the $\mathrm{T}^{\prime}$ phase in the various stages of the specimen are also listed in Table 3. In the bulk parts of the non-EPT and the various dynamic EPT specimens, a small amount of the residual $\mathrm{T}^{\prime}$ phase existed, the fractional EBSD intensity of the $\mathrm{T}^{\prime}$ phase was about 0.6 . In the neck zone of the dynamic 30A-EPT specimen, the amount of the $T^{\prime}$ phase increased considerably to a maximum. The fractional EBSD intensity 

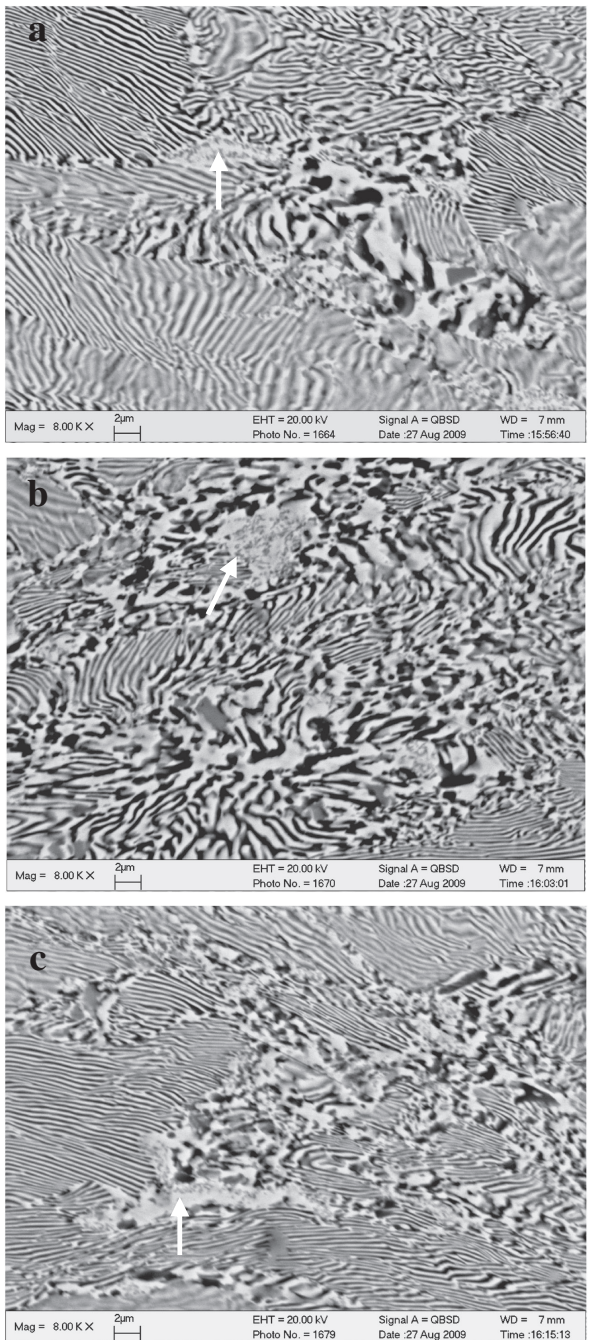

Fig. 2 BESM images of 30A EPT + tensile deformed ZA alloy specimens: (a) neck zone, (b) neck zone (near rupture part), and (c) rupture part.

of the $\mathrm{T}^{\prime}$ phase increased to 3.0. This means that the four phase transformation, $\varepsilon+\alpha \rightarrow \mathrm{T}^{\prime}+\eta$, occurred in the neck zone of the dynamic 30A-EPT specimen. In the rupture part of the dynamic 30A-EPT specimen, the fractional EBSD intensity of the $\mathrm{T}^{\prime}$ phase reduced to 1.4. This reveals that
Table 2 The lattice parameters for EBSD mapping deduced by TEM. ${ }^{5,20}$

\begin{tabular}{lccccc}
\hline & $\eta^{\prime}{ }_{\mathrm{S}}(\mathrm{hcp})$ & $\eta_{\mathrm{T}}^{\prime}(\mathrm{hcp})$ & $\varepsilon^{\prime}{ }_{\mathrm{T}}(\mathrm{hcp})$ & $\alpha^{\prime}{ }_{\mathrm{T}}(\mathrm{fcc})$ & $\mathrm{T}^{\prime}$ (bcc) \\
\hline$a_{0}(\mathrm{~A})$ & 2.707 & 2.694 & 2.733 & 4.072 & 2.967 \\
\hline$c_{0}(\mathrm{~A})$ & 4.924 & 4.950 & 4.621 & & \\
\hline$c_{0} / a_{0}$ & 1.818 & 1.837 & 1.690 & & \\
\hline
\end{tabular}

Table 3 Ratios of fractional EBSD intensities of $\eta_{\mathrm{S}}^{\prime}$ and $\eta_{\mathrm{T}}^{\prime}$ phases $\left(\eta_{\mathrm{S}}^{\prime} / \eta_{\mathrm{T}}^{\prime}\right)$ of the ZA alloy wires after Non-EPT and EPT with 10A-bulk, 30A-bulk, 30A-neck and 30A-rupture.

\begin{tabular}{|c|c|c|c|c|c|}
\hline EPT & None & $10 \mathrm{~A}$ bulk & 30A-bulk & 30A-neck & 30A-rupture \\
\hline$\eta_{\mathrm{S}}^{\prime}(\%)$ & 11.2 & 23.6 & 22.0 & 14.3 & 9.9 \\
\hline$\eta_{\mathrm{T}}^{\prime}(\%)$ & 7.6 & 15.4 & 18.7 & 17.2 & 11.0 \\
\hline \multirow[t]{2}{*}{$\eta_{\mathrm{S}}^{\prime} / \eta_{\mathrm{T}}^{\prime}$} & 1.5 & 1.5 & 1.2 & 0.8 & 0.9 \\
\hline & \multicolumn{3}{|c|}{$\eta_{\mathrm{S}}^{\prime} \rightarrow \eta_{\mathrm{T}}^{\prime}+\varepsilon_{\mathrm{T}}^{\prime}+\alpha_{\mathrm{T}}^{\prime}$} & \multicolumn{2}{|c|}{$\eta_{\mathrm{T}}^{\prime}+\varepsilon_{\mathrm{T}}^{\prime}+\alpha_{\mathrm{T}}^{\prime} \rightarrow \eta_{\mathrm{S}}^{\prime}$} \\
\hline
\end{tabular}

\begin{tabular}{llllll}
$\mathrm{T}^{\prime}$ & 0.5 & 0.7 & 0.6 & 3.0 & 1.4 \\
\hline & & & &
\end{tabular}

$\alpha+\varepsilon \rightarrow \eta+\mathrm{T}^{\prime} \quad \eta+\mathrm{T}^{\prime} \rightarrow \alpha+\varepsilon$

the reverse four phase transformation: $\mathrm{T}^{\prime}+\eta \rightarrow \varepsilon+\alpha$, occurred.

The $\langle 001\rangle$ pole figures of the $\mathrm{T}^{\prime}$ phase confirmed the above evolution of the $\mathrm{T}^{\prime}$ hase. Shown in Fig. 5 are the pole figures of the $\mathrm{T}^{\prime}$ phases in bulks of non-EPT (a), 10A-(b), 30A-(c) EPT specimens, and in neck zone (near rupture) (d) and rupture part (e) of the 30A-EPT specimens.

The project points of the $\mathrm{T}^{\prime}$ phase increased considerably in the neck zone of the 30A-EPT specimen than that in the bulk part of the specimen in both the pole figure. This means that the four phase transformation, $\varepsilon+\alpha \rightarrow \mathrm{T}^{\prime}+\eta$, occurred with increasing external stress in the neck zone of the 30AEPT specimen. In the rupture of the specimen, the projects of the $\mathrm{T}^{\prime}$ phase decreased. This implied that the reverse phase transformation: $\mathrm{T}^{\prime}+\eta \rightarrow \varepsilon+\alpha$, occurred.

Based on the lattice parameters and the indexed EBSKDP of the phases involved, EBSD examination convincingly confirmed the results of the BSEM examination.
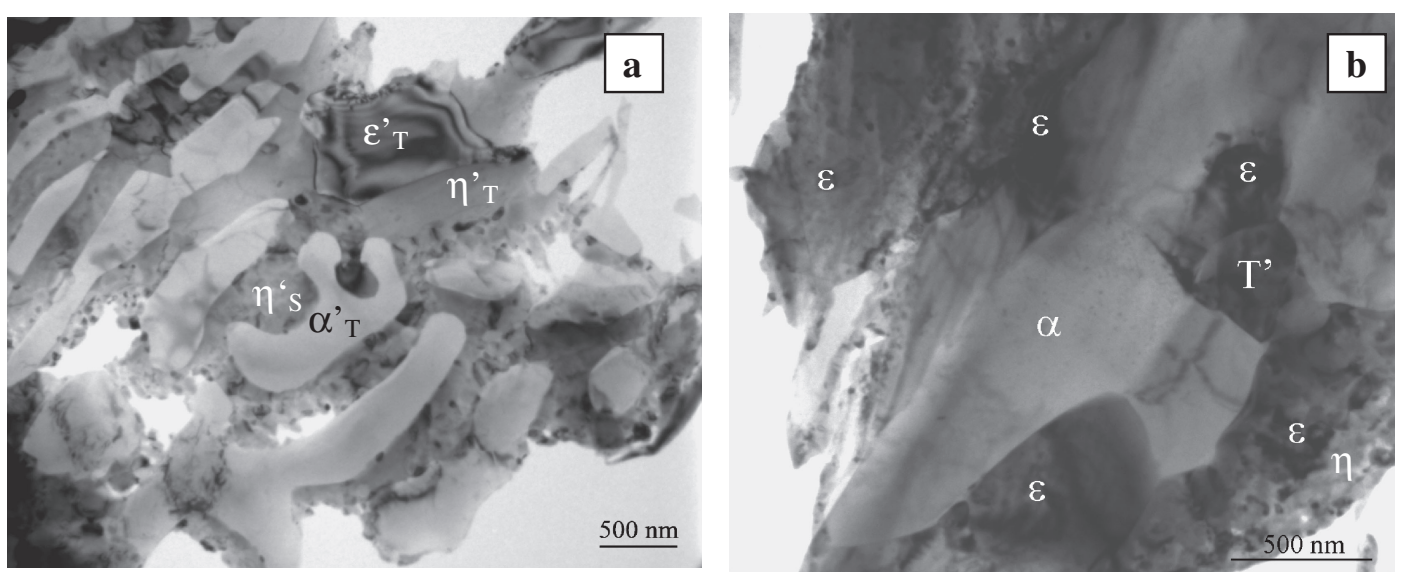

Fig. 3 TEM bright field images of (a) a static ${ }^{20}$ and (b) and a dynamic ${ }^{5)}$ EPT ZA alloy (ZA22) to show phase transformations: $\eta^{\prime} \mathrm{S} \rightarrow \eta^{\prime}{ }_{\mathrm{T}}+\varepsilon^{\prime}{ }_{\mathrm{T}}+\alpha^{\prime}{ }_{\mathrm{T}}$ in (a) and $\eta+\mathrm{T}^{\prime} \rightarrow \alpha+\varepsilon$ in (b), respectively. 

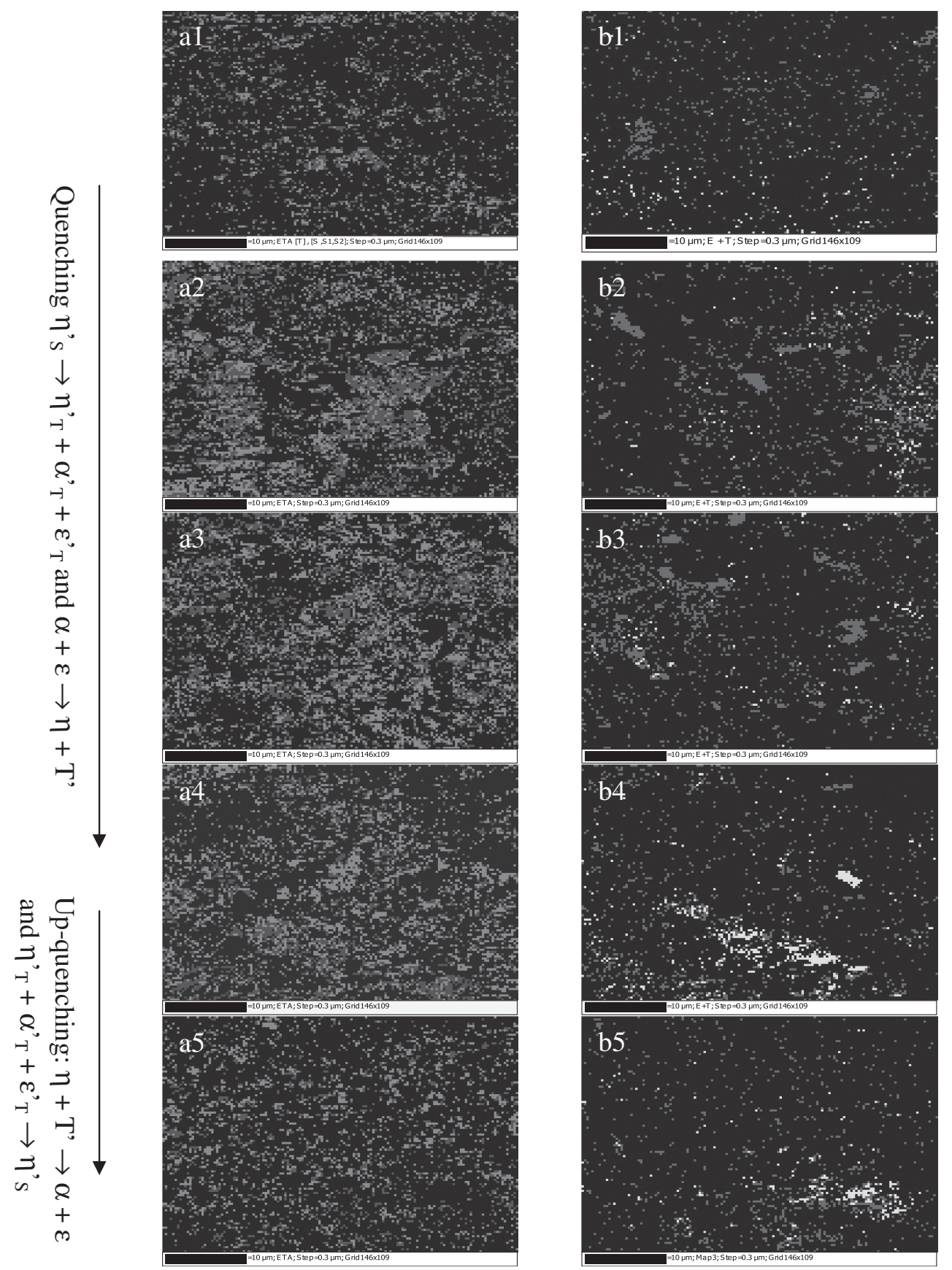

Fig. 4 EBSD mapping of $\eta_{\text {S }}^{\prime}$ (blue), $\eta_{T}^{\prime}$ (red) phases (a) and $\mathrm{T}^{\prime}$ (yellow) phases (b) in bulks of non-EPT (1), 10A-(2), 30A-(3) EPT specimens, and in neck zone (near rupture) (4) and rupture part (5) of the 30A-EPT specimens.

\section{Discussion}

\subsection{Driving force for phase transformations in dynamic EPT ZA alloy specimens}

The driving force for phase transformation in the dynamic EPT alloy specimens consists mainly of three parts:

$$
\Delta G=\Delta G_{\text {chem }}+\Delta G_{\text {ep }}+\Delta G_{\text {stress }},
$$

where $\Delta G_{\text {chem }}$ is the chemical Gibbs free energy, $\Delta G_{\text {ep }}$ the electrpulsing induced Gibbs free energy and $\Delta G_{\text {stress }}$ the stress induced Gibbs free energy. The electropulsing tremendously accelerated the phase transformations in two stages: (a) transformations from supersaturated state approaching the final stable state, $(\Delta G<0)$ and (b) reverse transformations from the final stable state a higher temperature state, $(\Delta G>0)$.

In the bulk part of the tensile deformed specimens, elastic deformation occurred. The elastic strain may be composed of the intrinsic elastic strain and the inelastic strain. ${ }^{29)}$ During the elastic deformation, new structural distortions, such as dislocations and vacancies were created. When electron wind passed through the specimens, parts of the electropulsing induced Gibbs free energy increments, $\Delta G_{\text {ep }}$ were exhausted through interaction between electrons and dislocation and vacancies which were created during the elastic deformation. Accordingly, the electropulsng induced $\Delta G_{\text {ep }}$ 


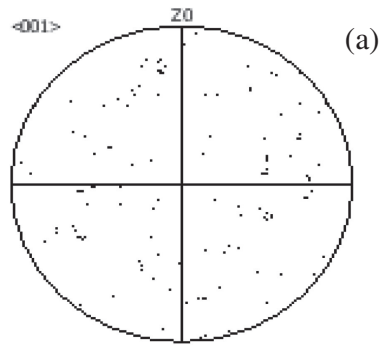

(c)
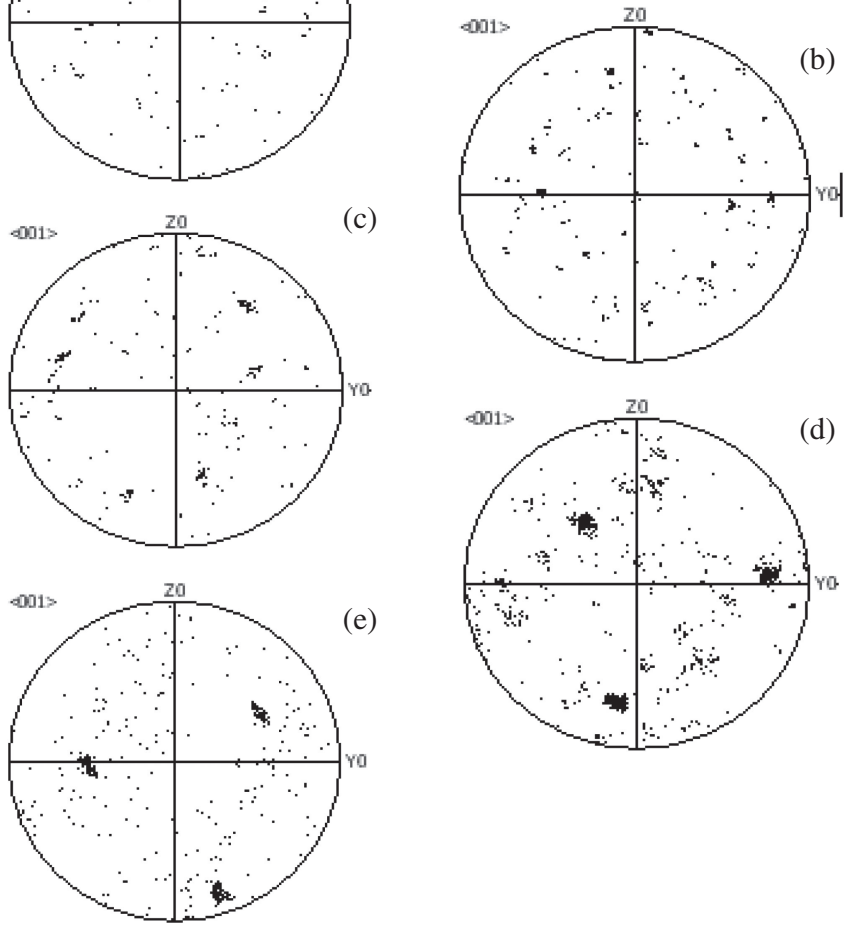

(e)

Fig. 5 Pole figures at the direction of the (001) planes of the $\mathrm{T}^{\prime}$ phases in bulks of non-EPT (a), 10A-(b), 30A-(c) EPT specimens, and in neck zone (near rupture) (d) and rupture part (e) of the 30A-EPT specimens.

for phase transformation was reduced. In consequence, under dynamic electropulsing, only phase transformation, $\eta_{\mathrm{S}}^{\prime} \rightarrow \eta_{\mathrm{T}}^{\prime}+\varepsilon_{\mathrm{T}}^{\prime}+\alpha_{\mathrm{T}}^{\prime}$, occurred in the bulk part of the dynamic EPT FC-ZA alloy specimen. But no $\varepsilon+\alpha \rightarrow$ $\mathrm{T}^{\prime}+\eta$, or reverse transformations: $\eta_{\mathrm{T}}^{\prime}+\varepsilon^{\prime}{ }_{\mathrm{T}}+\alpha^{\prime}{ }_{\mathrm{T}} \rightarrow \eta^{\prime}{ }_{\mathrm{S}}$ or $\mathrm{T}^{\prime}+\eta \rightarrow \varepsilon+\alpha$ were observed. Whilst in the bulk part of the static EPT alloy specimens, both phase transformations, $\eta_{\mathrm{S}}^{\prime} \rightarrow \eta_{\mathrm{T}}^{\prime}+\varepsilon_{\mathrm{T}}^{\prime}+\alpha_{\mathrm{T}}^{\prime}$, and $\varepsilon+\alpha \rightarrow \mathrm{T}^{\prime}+\eta$, were observed, as shown in Fig. 1(b). ${ }^{6}$ This means that the dynamic electropulsing accelerated less effectively phase transformation, than the static electropulsing did in the bulk part of the specimen.

In the neck zone, under both external stress and electropulsing, the total Gibbs free energy of the alloy was much increased. The driving force for the phase transformations, $\Delta G$, (i.e. $\Delta G_{\text {chem }}+\Delta G_{\text {ep }}+\Delta G_{\text {stress }}$ ), tremendously increased. The phase transformations were accelerated significantly in the dynamic electropulsing processing. The ratio $\left(\eta_{\mathrm{S}}^{\prime} / \eta_{\mathrm{T}}^{\prime}\right)$ reduced and $\mathrm{T}^{\prime}$ precipitates increased in the neck zone of the specimen.

Approaching the rupture part, the $\mathrm{T}^{\prime}$ phase precipitate increased to the maximum, as shown in Figs. 4(a) and (b). The final stable state, i.e. $\Delta G=0$, was reached in the neck zone of the dynamic 30A-EPT alloy specimen. The EBSD results confirmed what was observed in BSEM examinations, as shown in Figs. 1(a) and Fig. 2, respectively. These means that both $\eta_{\mathrm{S}}^{\prime} \rightarrow \eta_{\mathrm{T}}^{\prime}+\varepsilon_{\mathrm{T}}^{\prime}+\alpha_{\mathrm{T}}^{\prime}$ and $\varepsilon+\alpha \rightarrow \mathrm{T}^{\prime}+\eta$ occurred in a way of quenching. ${ }^{20)}$
In comparison, the tensile deformation induced four phase transformations, $\varepsilon+\alpha \rightarrow \mathrm{T}^{\prime}+\eta$, which was developed only in the rupture part, but not in the neck zone of the non-EPT alloy specimens. ${ }^{30)}$ This implies that electropulsing accelerated phase transformations.

However, in the case of static EPT, the $\mathrm{T}^{\prime}$ precipitates increased to maximum and the final stable state was reached in the neck zone of the static 15A-EPT alloy specimen. ${ }^{21)}$ This reveals that the dynamic EPT accelerated phase transformation less than the static EPT does. This is because during dynamic electropulsing, a part of $\Delta G_{\text {ep }}$ exhausted in interaction between electrons and those dislocations and vacancies deduced from tensile deformation. The driving force for the phase transformation decreased.

Upon further increasing tensile stresses, $\Delta G_{\text {stress }}$ was enhanced considerably in the rupture part of the dynamic 30A EPT specimens. The $\left(\Delta G_{\text {chem }}+\Delta G_{\text {ep }}+\Delta G_{\text {stress }}\right)$ became positive, i.e. $\Delta G>0$. Two reverse phase transformations occurred in a way of up-quenching. ${ }^{20)}$ Once the specimen was up-quenched and left from the final stable state ( $\left.\Delta G_{\text {chem }}=0\right)$, the $\Delta G_{\text {chem }}$ became negative again. The $\Delta G_{\text {ep }}+\Delta G_{\text {stress }}$ became the driving force against $\Delta G_{\text {chem }}$ (the anti-driving force) for the reverse phase transformations. The amount of the $\mathrm{T}^{\prime}$ phase precipitates decreased, i.e. $\mathrm{T}^{\prime}+\eta \rightarrow \varepsilon+\alpha$, and the $\eta_{\mathrm{S}}^{\prime} / \eta_{\mathrm{T}}^{\prime}$ increased, i.e. $\eta_{\mathrm{T}}^{\prime}+$ $\varepsilon^{\prime}{ }_{\mathrm{T}}+\alpha^{\prime}{ }_{\mathrm{T}} \rightarrow \eta^{\prime}{ }_{\mathrm{S}}$ occurred, as shown in Figs. 2(d), 4(a) and (b), respectively. Until $\Delta G_{\text {ep }}+\Delta G_{\text {stress }}=\Delta G_{\text {chem }}$, another stable state was reached at a higher temperature.

In conclusion, the driving force for the dynamic electropulsing induced phase transformation in the way of quenching consists mainly of $\left(\Delta G_{\text {ep }}+\Delta G_{\text {stress }}+\Delta G_{\text {chem }}\right)$, while that for the reverse phase transformations in the way of up-quenching is $\left(\Delta G_{\text {ep }}+\Delta G_{\text {stress }}-\Delta G_{\text {chem }}\right)$. The $\left(\Delta G_{\text {ep }}+\right.$ $\Delta G_{\text {stress }}$ ) becomes the driving force against $\Delta G_{\text {chem }}$, for the reverse phase transformations in the up-quenching stage.

\subsection{Correlation between phase transformations that occurred under dynamic electropulsing and during ageing processes}

Previous studies indicated that two eutectoid phase transformations; $\eta_{\mathrm{S}}^{\prime} \rightarrow \eta^{\prime}{ }_{\mathrm{T}}+\varepsilon^{\prime}{ }_{\mathrm{T}}+\alpha^{\prime}{ }_{\mathrm{T}}$ and decomposition of the $\varepsilon^{\prime}{ }_{\mathrm{T}}: \varepsilon^{\prime} \mathrm{T} \rightarrow \eta+\alpha+\mathrm{T}^{\prime}$, i.e. via $\varepsilon+\alpha \rightarrow \mathrm{T}^{\prime}+\eta$, occurred sequentially in various thermal and thermo-mechanical processes. ${ }^{30-33)}$ The former occurred at the early stage of ageing or in that part of the specimen with less external stress, corresponding to an equilibrium, $\beta+\varepsilon=\alpha+\eta$ at $276^{\circ} \mathrm{C}$. And the latter occurred at the prolonged stage of ageing or in that part of the specimen with higher external stress, correlating with another equilibrium, $\varepsilon+\alpha=\mathrm{T}^{\prime}+\eta$ at $268^{\circ} \mathrm{C}^{33)}$

The correlation between the phase transformations in the aged and in the dynamic EPT FC-ZA alloys is schematically shown in Fig. 6, where the reverse phase transformations are indicated by dashed lines. From Fig. 6, it can be seen that the dynamic electropulsing may accelerated phase transformation in two stages sequentially: (a) phase transformation in a way of quenching: $\eta_{\mathrm{S}}^{\prime} \rightarrow \eta^{\prime}{ }_{\mathrm{T}}+\varepsilon^{\prime}{ }_{\mathrm{T}}+\alpha^{\prime}{ }_{\mathrm{T}}$ and $\varepsilon+\alpha \rightarrow$ $\mathrm{T}^{\prime}+\eta$, and (b) reverse phase transformations in a way of up-quenching: $\mathrm{T}^{\prime}+\eta \rightarrow \varepsilon+\alpha$ and $\eta_{\mathrm{T}}^{\prime}+\varepsilon_{\mathrm{T}}^{\prime}+\alpha_{\mathrm{T}}^{\prime} \rightarrow \eta_{\mathrm{S}}^{\prime}$, depending on the driving force for the phase transformations $(\Delta G)$. 


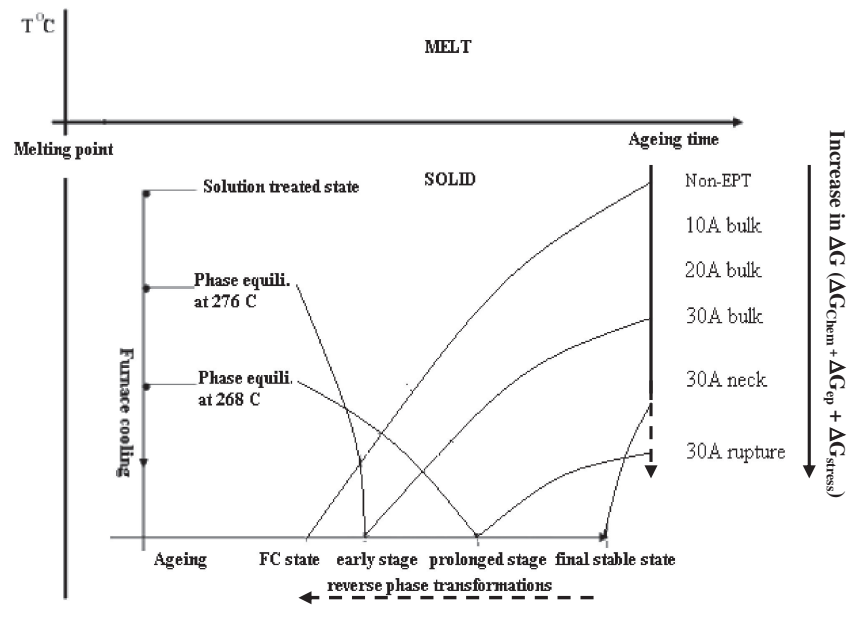

Fig. 6 Correlations between phase transformations in the aged and the dynamic EPT FC-ZA alloy (ZA22).

\subsection{Dynamic electropulsing kinetics}

Under electropulsing, the electron wind formed due to the knock-on collision of high rate electrons with atomic nuclei was beneficial to mobility of dislocations and vacancies. The transfer of energy from electrons directly to atoms was very much more effective than that in the traditional thermal and thermo-mechanical processes.,4,34) Under the impact of transient stress, the mobilized dislocations were moved very quickly, even at ultrasonic speeds. ${ }^{8)}$

As far as the diffusion-controlled phase transformations are concerned, electron migration may be important when considering the influence of an electric current. Both the motion of dislocations and quench-in vacancies, and precipitation rate are considerably dependent on the atomic diffusion flux, $J$. In the case of electropulsing, the $J$ consists of two parts, $J_{\mathrm{t}}$ and $J_{\mathrm{a}}$, where $J_{\mathrm{t}}$ is the flux of diffusion atoms caused by the thermal effect, and the $J_{\mathrm{a}}$ is the flux of the diffusion atoms due to the athermal effect. ${ }^{13-15)}$

The average atomic flux per second during multiple continuous electroppusling can be described as in the following equation: ${ }^{35)}$

$$
\begin{aligned}
J & =J_{\mathrm{t}}+J_{\mathrm{a}} \\
& =\frac{2 \pi D_{\mathrm{l}}}{\Omega \ln \left(\frac{R^{\prime}}{\gamma_{0}}\right)} \cdot\left(1+\frac{\delta_{\mathrm{c}}}{c_{0}}\right)+\frac{2 N \cdot D_{1} \cdot Z^{*} \cdot e \cdot \rho \cdot f \cdot j_{\mathrm{m}} \cdot \tau_{\mathrm{p}}}{\pi K T}
\end{aligned}
$$

where $D_{1}$ is the lattice diffusion coefficient, $N$ the density of the atom. The additional symbol $c_{0}$ is the average concentration of vacancy, $\delta_{\mathrm{c}}$ supersaturation concentration of vacancies, $r_{0}$ and $R^{\prime}$ the distances far from the dislocation where the vacancy concentrations are $c_{0}$ and $c_{0}+\delta_{\mathrm{c}}$, respectively; $T$ is the absolute temperature; $j_{\mathrm{m}}, f$ and $\tau_{\mathrm{p}}$ are peak current density, frequency and duration of each electropulse, respectively.

From the second part of the eq. (2), it can be seen that $J_{\mathrm{a}}$ is strongly dependent on the parameters of electropulsing, and increases strongly with the frequency $(f)$, duration of each electropulse $\left(\tau_{\mathrm{p}}\right)$, peak current density $\left(j_{\mathrm{m}}\right)$ and the duration of EPT $\left(t_{\text {ept }}\right)$, when temperature is constant. A high current density of dynamic EPT may accelerate dramatically the diffusional phase transformation.

In the present study, the current density is represented by the current intensity for the wire specimens of $1.5 \mathrm{~mm}$ in diameter.

During dynamic electropulsing, the thermal effect is influenced by interaction between electrons and dislocations and vacancies. As seen in the first part of the Equation, the supersaturation concentration of vacancy, $\delta_{c}$, is related to the thermal effect. The $\delta_{\mathrm{c}}$ increased under dynamic electropulsing, i.e. a combination of electropulsing and tensile deformation. When current density of electropulsing increases, the thermal effect of EPT became apparent. During the dynamic 30A-EPT, the temperature of the specimens was raised up to $50^{\circ} \mathrm{C}$, whilst the athermal effect of the electropulsing still played a dominant role in accelerating phase transformations. A part of the electropulsing induced driving force for phase transformations was exhausted, which resulted in decreasing the phase transformation rate in the dynamic EPT 30A-ZA alloy specimens. Under a combination of electropulsing and tensile deformation, the decompositions: $\eta_{\mathrm{S}}^{\prime} \rightarrow \eta_{\mathrm{T}}^{\prime}+\varepsilon_{\mathrm{T}}^{\prime}+\alpha_{\mathrm{T}}^{\prime}$ and $\varepsilon+\alpha \rightarrow \mathrm{T}^{\prime}+\eta$ were accelerated apparently in the neck zone of the dynamic 30AEPT specimen.

\section{Conclusions}

(1) By using EBSD, two hcp phases: $\eta_{\mathrm{S}}^{\prime}$ and $\eta_{\mathrm{T}}^{\prime}$, with a small difference of about $1 \%$ in lattice parameters (c/a) were discriminated. EBSD is a feasible and convincing technique in multiphase identification and in tracing phase transformations in dynamic EPT FC-ZA based alloy (ZA22).

(2) The dynamic electropulsing accelerated phase transformation of the FC ZA alloy 22 in two stages sequentially: (a) phase transformation in a way of quenching: $\eta_{\mathrm{S}}^{\prime} \rightarrow \eta_{\mathrm{T}}^{\prime}+\varepsilon_{\mathrm{T}}^{\prime}+\alpha_{\mathrm{T}}^{\prime}$ and $\varepsilon+\alpha \rightarrow$ $\mathrm{T}^{\prime}+\eta$, and (b) reverse phase transformations in a way of up-quenching: $\mathrm{T}^{\prime}+\eta \rightarrow \varepsilon+\alpha$ and $\eta_{\mathrm{T}}^{\prime}+\varepsilon_{\mathrm{T}}^{\prime}+$ $\alpha_{\mathrm{T}}^{\prime} \rightarrow \eta_{\mathrm{S}}^{\prime}$, depending on the current density and the external stresses.

(3) Because of the interaction between electrons and microstuctural defects, such as dislocation and vacancies induced by tensile deformation, a part of the electropulsing induced driving force for the phase transformations dissipated in the dynamic EPT FC-ZA alloy specimens. Therefore, dynamic electropulsing was less effective in accelerating phase transformations than static electropulsing.

\section{Acknowledgements}

The authors would like to express their sincere thanks to the Research Grant Council of Hong Kong Special Administration Region of the People's Republic of China for financial support (Project No. Polyu.5316/09E). Technical assistance from Mr. F. Y. F. Chan of the Electron Microscope Unit of The Hong Kong University and Mr. J. M. N. Yueng of Materials Research Center of The Hong Kong Polytechnic University is gratefully acknowledged. 


\section{REFERENCES}

1) O. A. Troiskii: Zh Eksp Teor. Fiz 10 (1969) 18-22.

2) A. F. Sprecher, S. L. Mamnna and H. Cornad: Acta Metall. 34 (1986) 1145-1162.

3) D. Yang and H. Conrad: Intermetallics 9 (2001) 943-947.

4) K. Okazaki, M. Kagawa and H. Conrad: Mater. Sci. Eng. A 45 (1980) 109-116

5) Y. H. Zhu, S. To, W. B. Lee, X. M. Liu, Y. B. Jiang and G. Y. Tang: Mater. Sci. Eng. A 501 (2009) 125-132.

6) S. To, Y. H. Zhu, W. B. Lee, X. N. Liu and Y. B. Jiang: Mater. Trans. 50 (2009) 2772-2777.

7) J. R. Lloyd: J. Phys. D, Appl. Phys. 32 (1999) R109.

8) R. P. Gupta, Y. Serruys, G. Brebec and Y. Adda: Phys. Rev. B 2 (1983) 669-674.

9) S. H. Xiao, J. D. Guo, S. D. Wu, G. H. He and S. X. Li: Scr. Mater. 46 (2002) 1-6.

10) Z. S. Xu, Z. H. Lai and Y. X. Chen: Sri. Metall. 22 (1988) 187-190.

11) Q. Li, Y. B. Xu, Z. H. Lai, L. T. Shen and Y. L. Bai: Mater. Sci. Eng. A 276 (2000) 250-256.

12) F. Wagner, N. Bozzolo, O. Van Landuyt and T. Grosdidier: Acta. Mater. 50 (2002) 1245-1259.

13) T. Hao, H. Tanimoto and H. Mizubayashi: Mater. Trans. 46 (2005) 2898-2907.

14) H. Mizubayashi, T. Takarashi and K. Nakamoto: Mater. Trans. 48 (2007) 1665-1670.

15) H. Conrad: Mater. Sci. Eng. A 287 (2000) 227-237.

16) Y. Onodera and K. I. Hirano: J. Mater. Sci. 11 (1976) 809-816.

17) V. E. Gromov, L. B. Zuev, V. I. Baraikin and V. Ya: Russ. Phys. J. 39
(1996) 257-261.

18) Y. Z. Zhou, J. D. Guo, W. Zhang and G. H. He: J. Mater. Res. 17 (2002) 3012-3014.

19) V. V. Stolyarov: Mater. Sci. Eng. A 503 (2009) 18-20.

20) Y. H. Zhu, S. To, W. B. Lee, X. M. Liu, Y. B. Jiang and G. Y. Tang: J. Mater. Res. 24 (2009) 2661-2669.

21) S. To, Y. H. Zhu, W. B. Lee, X. M. Liu, Y. B. Jiang and G. Y. Tang: Appl. Phys. A 96 (2009) 939-944.

22) S. To, Y. H. Zhu, W. B. Lee, G. Y. Tang, X. M. Liu and Y. B. Jiang: Mater. Trans. 50 (2009) 1105-1112.

23) Y. B. Jiang, G. Y. Tang, C. H. Shek, Y. H. Zhu and Z. H. Xu: Acta Mater. 57 (2009) 4797-4808.

24) Y. Dolinsky and T. Elperin: Phys. Rev. B 50 (1994) 52-58.

25) Y. H. Zhu, W. B. Lee, C. F. Yeung and T. M. Yue: Mater. Charact. 46 (2001) 19-23.

26) Y. H. Zhu, W. B. Lee and S. To: Mater. Sci. Eng. A 348 (2003) 6-14.

27) S. To, Y. H. Zhu and W. B. Lee: J. Microscopy 225 (2007) 170-174.

28) A. F. Gourgues-Lorenzon: Int. Mater. Rev. 52 (2007) 65-128.

29) H. Mizubayashi, T. Usui and H. Tanimoto: J. Non-Cryst. Solids 312 (2002) 542-546.

30) Y. H. Zhu, G. Torres-Villasenor and C. Pina: J. Mater. Sci. 29 (1994) 1549-1552.

31) Y. H. Zhu and W. B. Lee: Mater. Sci. Eng. A 293 (2000) 95-101.

32) Y. H. Zhu, H. C. Man, H. J. Dorantes-Rosales and W. B. Lee: J. Mater. Sci. 38 (2003) 2925-2934.

33) Y. H. Zhu: Mater. Trans. 45 (2004) 3083-3097.

34) F. R. Nabarro: Theory of crystal dislocation, (Clrendon Press, Oxford, 1976) p. 529.

35) Y. B. Jiang, G. Y. Tang, C. H. Shek, Y. H. Zhu, L. Guan, S. N. Wang and Z. H. Xu: J. Mater. Res. 23 (2008) 2685-2690. 